\title{
EFFECT OF LONG-TERM ADMINISTRATION OF ARSENIC(III) AND BROMINE WITH AND WITHOUT SELENIUM AND IODINE SUPPLEMENTATION ON THE ELEMENT LEVEL IN THE THYROID OF RAT
}

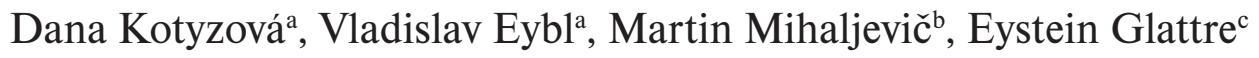 \\ a Department of Pharmacology and Toxicology, Charles University in Prague, Faculty of Medicine in Pilsen, Karlovarská \\ 48, CZ-301 66 Pilsen, Czech Republic \\ ${ }^{b}$ Charles University, Faculty of Science, 12000 Prague, Czech Republic \\ c Cancer Registry of Norway, N-0310, Oslo, Norway \\ e-mail:dana.kotyzova@lfp.cuni.cz
}

Received: June 10, 2005; Accepted: September 25, 2005

Key words: Iodine/Thyroid gland/Selenium/Bromine/Arsenic

The aim of this study was to evaluate the influence of arsenic and bromine exposure with or withour iodine and selenium supplementation on the element level in the thyroid of rats. Four major groups of Wistar female rats were fed with respective diets: group A - standard diet, group B - iodine rich diet (10 mg I/ $\mathrm{kg}$ food), group C - selenium rich diet ( $1 \mathrm{mg} \mathrm{Se} / \mathrm{kg}$ ) and group D - iodine and selenium rich diet (as in group B and C). Each group was divided into four subgroups per 7 animals each receiving either $\mathrm{NaAsO}_{2}$ ip $\left(6.5 \mathrm{mg} \cdot \mathrm{kg}^{-1}\right.$ twice a week for two weeks and $3.25 \mathrm{mg} . \mathrm{kg}^{-1}$ for six weeks) or $\mathrm{KBr}$ in drinking water $\left(58.8 \mathrm{mg} . \mathrm{l}^{-1}\right)$ for 8 weeks or combined administration of both substances. Remaining subgroup served as controls. After 8 weeks thyroid glands were analyzed by ICP-MS for As, $\mathrm{Br}, \mathrm{Se}$, and I content. The exposition of rat to arsenic or bromine causes the accumulation of these elements in the thyroid gland ( $\sim 18 \mathrm{ppm}$ of As, $\sim 90 \mathrm{ppm}$ of $\mathrm{Br})$ and significantly affects iodine and selenium concentration in the thyroid. In iodine and/or selenium supplemented rats the bromine intake into the thyroid was lowered to $\sim 50 \%$ of the level in unsupplemented animals. Also selenium thyroid level elevated due to $\mathrm{KBr}$ administration was lowered by iodine supplementation in the diet. The accumulation of arsenic in the thyroid was not influenced by selenium or iodine supplementation; however, As(III) administration increased iodine thyroid level and suppressed selenium thyroid level in selenium or iodine supplemented group of animals.

\section{INTRODUCTION}

An increased incidence of thyroid cancer has been reported especially in the female population of the United States $^{1,2}$, in most other affluent countries (Scandinavia, Israel $)^{3}$ and as well in the Czech Republic ${ }^{4}$. According to epidemiological, clinical and experimental studies, both the dietary deficiency and excess of iodine have been associated with increased risk of thyroid carcinomas ${ }^{5-8}$. In this connection, the effect of salt water fish and shellfish consumption as a measure of iodine exposure has been discussed $^{9-11}$.

Apart from iodine, which is the main constituent of thyroid hormones, a second essential trace element - selenium - is required for appropriate thyroid hormone synthesis, activation and metabolism. Adequate supply with these essential elements needs to be provided to the organism either by a balanced diet or supplementation ${ }^{12-14}$.

However, other dietary substances may be present in seawater, and subsequently taken up by fish and seafood, that interact with iodine metabolism or may be carcinogenic to the thyroid without any relation to iodine metabolism ${ }^{15}$. One of such dietary factors of seafood origin is bromine, the goitrogenic effect of which cannot be excluded due to its chemical relationship with iodine. Its increasing use in both, industry and agriculture introduces bromine into the alimentary chain in ever-growing quantities. Another sea-water bound element is carcinogenic metalloid arsenic; its interaction with selenium has been known for more than half a century ${ }^{16}$.

This study was undertaken to estimate the influence of arsenic and bromine exposure on selenium and iodine thyroid content in experimental animals fed standard and iodine- or selenium-rich diet.

\section{MATERIALS AND METHODS}

\section{Animals and diets}

Female Wistar rats (Charles River, FRG) weighing 90-100 g were used for the experiments. After adaptation period of 5 days, the animals were assigned to four experimental groups being fed with different experimental diets.

Control group (A) received a standard diet (C 1042, Altromin, Lage, FRG), containing $17 \%$ protein, $57 \%$ carbohydrates, $5 \%$ fat, $3 \%$ fiber (cellulose) $8 \%$ of a mixture of vitamins and salts and $10 \%$ of water. Selenium content 
in the diet was $0.252 \mathrm{mg} / \mathrm{kg}$ food and iodine content was $0.151 \mathrm{mg} / \mathrm{kg}$ food; iodine supplemented group (B) received the standard diet with the addition of $10 \mathrm{mg}$ iodine $/ \mathrm{kg}$ food; selenium supplemented group (C) received the standard diet with the addition of $1 \mathrm{mg}$ selenium $/ \mathrm{kg}$ food; selenium and iodine supplemented group (D) received the standard diet with the additions as in group B and C. Animals were fed their respective diets for 8 weeks.

For each of four separate groups in which one of the four diets was supplemented, 28 animals were used and divided into four subgroups ( $\mathrm{n}=7$ in each subgroup) according to following scheme: subgroup 1 received no additional treatment; subgroup 2 received $\mathrm{NaAsO}_{2}$ (Sigma Chemical Co.), ip, $6.5 \mathrm{mg} / \mathrm{kg}$ body weight twice per week for two weeks and $3.25 \mathrm{mg} / \mathrm{kg}$ bw for six weeks; subgroup 3 received $\mathrm{KBr}$ (Sigma Chemical Co.) $58 \mathrm{mg} / \mathrm{l}$ in drinking water; subgroup 4 - received $\mathrm{NaAsO}_{2}$ as in subgroup 2 and $\mathrm{KBr}$ as in subgroup 3 .

The animals were housed under conditions of constant humidity, temperature and light/dark cycles $12 \mathrm{~h} / 12 \mathrm{~h}$. They had free access to drinking water and food. Diets were replaced daily, body weights were determined weekly.

\section{Sample preparation and analytical procedures}

At the end of 8-week experimental period the animals were sacrificed under ether anesthesia by cutting jugular veins. The thyroids were excised, weighed immediately, sealed in aluminum foil and stored frozen at $-20^{\circ} \mathrm{C}$ until analysis.

Digestion of thyroid glands was carried out in $30 \mathrm{ml}$ Teflon vials (Savillex) using $2 \mathrm{ml}$ of concentrated nitric acid (purris p.a., Fluka Chemie, Switzerland), capped and left overnight on a heating desk at $150{ }^{\circ} \mathrm{C}$. The content in vials was almost evaporated, and then diluted with $2 \%$ $\mathrm{HNO}_{3}$. As an internal standard, $10 \mathrm{ppb}$ of In (Astasol, Analytica Ltd., Czech Rep.) was added.

Element analysis was performed by ICP-MS spectrometer (PQ3, VG Elemental); sample solutions were brought into nebulizer by means of peristaltic pump. Following isotopes were measured: ${ }^{75} \mathrm{As},{ }^{79} \mathrm{Br},{ }^{127} \mathrm{I},{ }^{82} \mathrm{Se}$ and ${ }^{115} \mathrm{In}$.

Digestion and analysis were checked by the measurement of the reference material (8414 Bovine Muscle Powder, NIST, Washington DC).
The element contents are expressed in micrograms of the element measured per gram of wet tissue weight $\left[\mu \mathrm{g} \cdot \mathrm{g}^{-1} \mathrm{wtw}\right]$.

\section{Statistical analysis}

All results are presented as the arithmetical mean \pm standard deviation (SD). Student's $t$-tests were performed to obtain levels of significance between the groups. Number of animals $(n)$ used per group are stated in the tables.

\section{RESULTS}

The growth curves were similar in all groups of animals supplemented by respective diets. The administration of arsenic (III) and/or potassium bromide did not exhibit any influence on the body weight increments within the groups. The average body weight gains in animals after eight-week supplementation with iodine- and/or seleniumenriched diet are given in Table 1.

Significant decrease in the average body weight gain was observed in rats supplemented with selenium enriched diet.

The results of arsenic, bromine selenium and iodine determination in the rat thyroid gland are summarized in Table 2. Since the standard diet lacked arsenic and bromine, these elements were not detectable in non-treated animals.

Arsenic. In As (III) and As (III) + KBr treated animals of control group $\mathrm{A}$, the concentration of arsenic reached the level of 18.0 and $18.9 \mu \mathrm{g} / \mathrm{g}$ wet tissue, respectively. The level remained unaffected by iodine supplementation. In selenium supplemented animals the concentration of arsenic was enhanced in group C2 compared to groups $\mathrm{C} 4$ and D2. In the other groups the additional administration of bromine together with arsenic did not cause any difference in arsenic concentration in the thyroid.

Bromine. In $\mathrm{KBr}$ and $\mathrm{KBr}+\mathrm{As}$ (III) treated rats the bromine content in thyroid gland was elevated to $\sim 90 \mathrm{ppm}$. Both, selenium and iodine enriched diet sig-

Table 1. Effect of the diet supplementation on the average weight gain of rats

\begin{tabular}{|c|c|c|}
\hline Subgroup & Diet & $\begin{array}{c}\text { weight gain } \\
\text { [\% of starting weight] }\end{array}$ \\
\hline A1 & Standard diet & $174.7 \pm 12.7$ \\
\hline B1 & Iodine rich diet & $150.6 \pm 18.4$ \\
\hline C1 & Selenium rich diet & $131.0 \pm 23.1$ * \\
\hline D1 & Iodine + Selenium rich diet & $153.9 \pm 14.1$ \\
\hline
\end{tabular}

Groups are defined in the text; $n=7$ animals per group. Values represent mean $\pm \mathrm{SD}^{*} \mathrm{P}<0.01$ vs. control subgroup A1 
Table 2. Concentration of arsenic, bromine, selenium and iodine in the thyroid gland of rats fed for eight weeks standard, iodine and/or selenium enriched diet combined with arsenic(III) and/or potassium bromide treatment.

\begin{tabular}{|c|c|c|c|c|c|}
\hline Treatment & $n$ & $\begin{array}{c}\text { As } \\
{\left[\mu \mathrm{g} \bullet \mathrm{g}^{-1} \mathrm{wtw}\right]}\end{array}$ & $\begin{array}{c}\mathbf{B r} \\
{\left[\mu \mathrm{g} \cdot \mathrm{g}^{-1} \mathrm{wtw}\right]}\end{array}$ & $\begin{array}{c}\text { Se } \\
{\left[\mu \mathrm{g} \bullet \mathrm{g}^{-1} \mathrm{wtw}\right]}\end{array}$ & $\frac{\mathbf{I}}{\left[\mu \mathrm{g} \bullet \mathrm{g}^{-1} \mathrm{wtw}\right]}$ \\
\hline \multicolumn{6}{|l|}{ A. Standard diet } \\
\hline 1. Control & 7 & n.d. & n.d. & $0.20 \pm 0.02$ & $82.5 \pm 42.1$ \\
\hline 2. As $s^{I I I}$ & 7 & $18.0 \pm 5.2 *$ & n.d. & $0.28 \pm 0.12$ & $83.5 \pm 44.6$ \\
\hline 3. $\mathrm{KBr}$ & 7 & n.d. & $91.1 \pm 32.2 *$ & $0.53 \pm 0.11 *$ & $73.7 \pm 28.9$ \\
\hline 4. $\mathrm{KBr}+\mathrm{As}^{\mathrm{III}}$ & 6 & $18.9 \pm 6.4^{*}$ & $90.2 \pm 22.9 *$ & $0.55 \pm 0.10^{*}$ & $91.6 \pm 16.9$ \\
\hline \multicolumn{6}{|l|}{ B. Iodine enriched diet } \\
\hline 1. Control & 7 & n.d. & n.d. & $0.22 \pm 0.08$ & $54.1 \pm 33.6$ \\
\hline 2. $A s^{I I I}$ & 7 & $18.9 \pm 7.4^{*}$ & n.d. & $0.26 \pm 0.04$ & $120.0 \pm 16.7^{* \#}$ \\
\hline 3. $\mathrm{KBr}$ & 7 & n.d. & $48.7 \pm 6.0^{* \#}$ & $0.38 \pm 0.06^{\text {*\# }}$ & $57.7 \pm 48.2$ \\
\hline 4. $\mathrm{KBr}+\mathrm{As}^{\mathrm{III}}$ & 6 & $18.9 \pm 7.6^{*}$ & $48.5 \pm 11.0^{* \#}$ & $0.37 \pm 0.09 * \#$ & $82.1 \pm 42.7$ \\
\hline \multicolumn{6}{|c|}{ C. Selenium enriched diet } \\
\hline 1. Control & 7 & n.d. & n.d. & $0.34 \pm 0.09^{\#}$ & $148.7 \pm 40.5^{\#}$ \\
\hline 2. As $s^{I I I}$ & 6 & $20.7 \pm 4.0^{*}$ & n.d. & $0.27 \pm 0.05$ & $171.7 \pm 27.5^{\#}$ \\
\hline 3. $\mathrm{KBr}$ & 7 & n.d. & $58.3 \pm 8.6^{* \#}$ & $0.50 \pm 0.13^{\#}$ & $144.7 \pm 10.9^{\#}$ \\
\hline 4. $\mathrm{KBr}+\mathrm{As}^{\mathrm{III}}$ & 7 & $15.2 \pm 2.7^{*}$ & $51.0 \pm 10.3^{* \#}$ & $0.40 \pm 0.06^{\#}$ & $134.6 \pm 24.8^{\#}$ \\
\hline \multicolumn{6}{|c|}{ D. Iodine + Selenium enriched diet } \\
\hline 1. Control & 7 & n.d. & n.d. & $0.29 \pm 0.07^{\#}$ & $126.4 \pm 35.2^{\#}$ \\
\hline 2. As ${ }^{I I I}$ & 7 & $15.9 \pm 4.4^{*}$ & n.d. & $0.22 \pm 0.03^{\#}$ & $127.1 \pm 63.3$ \\
\hline 3. $\mathrm{KBr}$ & 7 & n.d. & $34.4 \pm 11.4^{* \#}$ & $0.33 \pm 0.06^{\#}$ & $86.2 \pm 50.1$ \\
\hline 4. $\mathrm{KBr}+\mathrm{As}^{\mathrm{III}}$ & 7 & $15.9 \pm 3.6^{*}$ & $35.9 \pm 7.3^{* \#}$ & $0.32 \pm 0.04^{\#}$ & $109.6 \pm 32.0$ \\
\hline
\end{tabular}

Data represent mean $\pm \mathrm{SD}$, n.d. = not detectable

Significant differences $\mathrm{p}<0.05$ * versus control of the same group;

\# versus corresponding subgroup of control group A

nificantly diminished bromine uptake into the thyroid of all animals compared to control group A. Iodine supplementation (group B) resulted in the decrease of bromine content to $54 \%$ of A3 and A4 control groups. Selenium supplementation (group C) decreased the bromine level to $\sim 60 \%$, and the combined iodine and selenium supplementation (group D) to $\sim 40 \%$ of A3, A4 control groups. Additional treatment with As(III) did not affect the levels of bromine in the thyroid.

Selenium. Selenium supplementation enhanced $\mathrm{Se}$ content in the thyroid from $0.20 \pm 0.02$ (A1) to $0.34 \pm$ $0.09 \mu \mathrm{g} / \mathrm{g}$ wet tissue (C1), and in combination with iodine supplementation to $0.29 \pm 0.07$ (D1). No effect of iodine supplementation on selenium thyroid level was found.
Selenium concentration was enhanced in all $\mathrm{KBr}$ and $\mathrm{KBr}$ + As(III) treated rats compared with respective control subgroup - to $\sim 270 \%$ in group A, to $170 \%$ in group B and to $150 \%$ in group C. In animals supplemented with combined iodine and selenium enriched diet (group D) no such effect was observed. In selenium supplemented rats the As(III) treatment caused a significant decrease of selenium thyroid level to $80 \%$ of respective control subgroups C1, D1 level.

Iodine. In control animals fed standard diet the iodine content in the thyroid remained unaffected by either $\mathrm{KBr}$ or As(III) treatment. Iodine supplementation exerted no effect on thyroid iodine level (group B) compared to group A. Selenium supplementation caused significant elevation 
of iodine content in all subgroups compared to group A, the highest level being in As(III) treated rats (C2). In selenium and iodine supplemented rats (group D) the increase was significant in control rats only (D1).

\section{DISCUSSION}

In the present study the eight-week administration of sodium arsenite to female rats (twice a week, $6.5 \mathrm{mg} / \mathrm{kg}$ bw, ip, for 2 week and $3.25 \mathrm{mg} / \mathrm{kg}$ bw, ip, for six week) and/or potassium bromide (58 $\mathrm{mg} / 1$ in drinking water) did not lead to any obvious signs of toxicity; no significant differences in the weight gain evolution were found between treated and untreated animals within each group fed respective diet.

The administration of selenium-rich diet $(1.25 \mathrm{mg} / \mathrm{kg}$ food) for 8 weeks resulted in a decrease of weight gain compared to animals fed standard diet (Table 1) and could reflect some slight toxic effect of selenium supplementation at this level. However, this does not correspond to the results of long term (8-10 weeks) selenium supplementation experiments in which the selenium content in animal diet up to $2 \mathrm{mg} \mathrm{Se} / \mathrm{kg}$ food was referred in Wistar rats to be still a physiological value ${ }^{17}$. The dietary excess of iodine ( $10 \mathrm{mg} / \mathrm{kg}$ food) had no effect on the weight gain.

The progressive increase in dietary content of iodine from $0.15 \mathrm{mg}$ to $10 \mathrm{mg} / \mathrm{kg}$ food did not result in an increase in thyroidal iodine concentration in control animals (group B1). These findings are in accordance with the recently published data assuming the high dietary iodine supply (>0.8 mg/ kg food) to overcharge compensatory capacity of iodine homeostasis with the consequence of iodine accumulation in extrathyroidal tissues (esp. skin) $\left(\right.$ ref. $\left.{ }^{18}\right)$. On the other hand, the increase in dietary selenium from $0.25 \mathrm{mg}$ to $1.25 \mathrm{mg} / \mathrm{kg}$ of food (group $\mathrm{C} 1$ ) resulted in enhanced selenium concentration in the thyroid as well as in elevated iodine thyroid level.

In 1974, the thyroid-toxic properties of bromide ion were observed by Van Logten et al., pointing to impairment of thyroid function ${ }^{19}$. Later the inhibition of iodine uptake was claimed to be one of possible mechanism of action on the thyroid gland ${ }^{20}$. Our data demonstrate that bromine accumulates easily in the thyroid. In agreement with recently published data ${ }^{21,22}$ the uptake of bromine into the thyroid was found to be dependent on the stage of iodine supply. In animals fed iodine enriched diet the bromine intake into the thyroid was lowered to $\sim 50 \%$ of bromine thyroid level of animals fed standard diet. Combined iodine and selenium supplementation resulted in an additive protective effect. The concentration of bromide ions administered in our experiment has not reached the critical concentration to contribute to lowering iodine uptake into thyroid gland; however a strong elevating effect on selenium thyroid level was seen, moderated by iodine supplementation.

Arsenic and selenium are metalloids with similar chemical properties and metabolic fates. Inorganic arsenic has been shown to modify metabolism of selenium and influence the anti-carcinogenic activity of inorganic and organic selenium compounds ${ }^{23,24}$. Some data also demonstrate that pre- or co-exposure to inorganic selenium exerts protective effect against toxicity of arsenic ${ }^{25-27}$. In our study the level of arsenic cumulation in the thyroid was not significantly influenced by dietary selenium supplementation. However, the administration of arsenite suppressed the access of Se into the thyroid of selenium supplemented animals (group C2, D2).

In view of the results presented, it can be concluded that arsenic and bromine have been shown to influence significantly the thyroid level of iodine and selenium, both closely associated with thyroid metabolism. The potential occurrence of simultaneous exposure to these elements in human population deserves further studies designed to clarify the nature and effect of these interactions.

\section{ACKNOWLEDGEMENT}

This study was supported by the Cancer Registry of Norway, Oslo, Norway and by the Grant Agency of the Czech Republic (No. 305/05/0344).

\section{REFERENCES}

1. Ron E. Thyroid cancer. In: Schottenfeld D, Fraumeni JF, Jr, editors. Cancer Epidemiology and Prevention, Chapt. 46. Second Edition. New York: Oxford University Press, 1996. p. 1000-21.

2. Ronckers CM, McCarron P, Ron E. (2005) Thyroid cancer and multiple primary tumors in the SEER cancer registries 1 . Int $\mathrm{J}$ Cancer - Epub ahead of print.

3. Franceschi S. (1998) Iodine intake and thyroid carcinoma A potential risk factor. Exp Clin Endocrinol Diabetes 106, Suppl 3, S39-S43.

4. Pecen L, Roušarová M, Koukalová H, Široký P. (1999) The epidemiology of thyroid gland tumors in the Czech Republic, according to the data of the national oncological register. Biomarkers and Environment 3, 7.

5. Axelrad AA, Leblond CP. (1955) Induction of thyroid tumors in rats by low iodine diet. Cancer $8,339-67$.

6. Wolff J. (1969) Iodine goiter and the pharmacologic effects of excess iodide. Am J Med 40, 58-66.

7. Kanno J, Matsuoka C, Furuta K, Onodera H, Miyajima H, Maekawa A, Hayashi Y. (1990) Tumor-promoting effect of goitrogens on the rat thyroid. Toxicologic Pathology 18, 239-46.

8. Kanno J, Onodera H, Furuta K, Maekawa A, Kasuga T, Hayashi Y. (1992) Tumor-promoting effects of both iodine deficiency and iodine excess in the rat thyroid. Toxicologic Pathology 20, 226-35.

9. Frich L, Akslen LA, Glattre E. (1997) Increased risk of thyroid cancer among Norwegian women married to fishery workers a retrospective cohort study. Br J Cancer 76, 385-9.

10. Venturi S, Donati FM, Venturi A, Venturi M, Grossi L, Guidi A. (2000) Role of iodine in evolution and carcinogenesis of thyroid, brest and stomach. Adv Clin Path 4, 11-27.

11. Horn-Ross PL, Moris JS, Lee M, West DW, Whitemore AS, McDougal IR, Nowels K, Stewart SL, Spate VL, Shiau AC, Krone MR. (2001) Iodine and thyroid cancer risk among women in a multiethnic population: the Bay Area Thyroid Cancer Study. Cancer Epidemiol Biomarkers Prev 10, 979-85.

12. Köhrle J. (1999) The trace element selenium and the thyroid gland. Biochimie 81, 527-33.

13. Arthur JR, Becket GJ, Mitchel JH. (1999) The interaction between selenium and iodine deficiencies in man and animals. Nutrition research Reviews 12, 55-73. 
14. Kvičala J, Zamrazil V. (2003) Effect of iodine and selenium upon thyroid function. Cent Eur J Public Health 11, 107-13.

15. Gaitan E. (1997) Effects of environmental agents on thyroid function. Pharmacotherapeutics of Thyroid Gland 128, 301-17.

16. Moxon AL, De Bots KP. (1939) The influence of arsenic and certain other elements on the toxicity of seleniferous grains. J Nutr $18,447$.

17. Coudray C, Hida H, Boucher F, Tirard V, DeLeiris J, Favier A. (1996) Effect of selenium supplementation on biological constants and antioxidant status in rats. J Trace Elements Med Biol 10, 129.

18. Kirchgessner M, He J, Windisch M. (1999) Homeostatic adjustments of iodine metabolism and tissue iodine to widely varying iodine supply in I-125 labeled rats. J Animal Physiol Animal Nutrition 82, 238-50.

19. Van Logten MJ, Wolthuis M, Rauws AG, Kroes R, Den Tonkelaar EM, Berkvens H, Van Esch GJ. (1974) Semichronic toxicity of sodium bromide in rats. Toxicology 2, 257-67.

20. Van Leeuwen FXR, Hanemaaijer R, Loeber JG. (1988) The effect of sodium bromide on thyroid function. Arch Toxicol, Suppl. 12, 97.
21. Vobecký M, Babický A, Lener J, Pavelka S. (1997) Biological halflife of bromine in the rat thyroid. Physiol Res 46, 385-9.

22. Velický J, Titlbach M, Lojda Z, Dušková J, Vobecký M, Štrbák V, Raška I. (1998) Long-term action of potassium bromide on the rat thyroid gland. Acta Histochem 100, 11-23.

23. Ip C, Ganther H. (1988) Efficacy of trimethylselenonium versus selenite in cancer chemoprevention and its modulation by arsenite. Carcinogenesis 9, 258-62.

24. Vadhanavikit S, Ip C, Ganther HE. (1993) Metabolites of sodium selenite and methylated selenium compounds administered at cancer chemoprevention levels in rats. Xenobiotika 23, 731-45.

25. Glattre E, Mravcova A, Lener J, Vobecky M, Egertova E, Mysliveckova M. (1995) Study of distribution and interaction of arsenic and selenium in rat thyroid. Biol Trace Elem Res 49, 177-86.

26. Biswas S, Talukder G, Sharma A. (1999) Prevention of cytotoxic effects of arsenic by short-term dietary supplementation with selenium in mice in vivo. Mutat Res 441, 155-60.

27. Styblo M, Thomas DJ. (2001) Selenium modifies the metabolism and toxicity of arsenic in primary rat hepatocytes. Toxicol Appl Pharmacol 172, 52-61. 